\title{
Evaluation of $\mathrm{RbCl}$ and $\mathrm{CrCl}_{3}$ as markers of Triatoma brasiliensis (Hemiptera: Reduviidae) nymphs: persistence and influence of $\mathbf{R b}$ and $\mathrm{Cr}$ on triatomine biology
}

\author{
Otília Sarquis', Lívia S Oliveira1', Reginaldo Rego², Jaylei M Gonçalves³, \\ Marli M Lima', Rafael Maciel-de-Freitas ${ }^{2} /+$ \\ 'Laboratório de Ecoepidemiologia de Doença de Chagas Laboratório de Transmissores de Hematozoários, \\ Instituto Oswaldo Cruz-Fiocruz, Rio de Janeiro, RJ, Brasil ' ${ }^{3}$ aboratório de Contaminantes Inorgânicos, \\ Departamento de Química, Instituto Nacional de Controle e Qualidade em Saúde-Fiocruz, Rio de Janeiro, RJ, Brasil
}

In order to mark Triatoma brasiliensis, the vector of Chagas disease in Brazil, two chemical compounds, rubidium chloride $(\mathrm{RbCl})$ and chromium chloride $\left(\mathrm{CrCl}_{3}\right)$, were tested. First, $199 \mathrm{N2}-\mathrm{N} 5$ nymphs were fed on blood with $0.025 \mathrm{M} \mathrm{RbCl}$. Rb marker positivity ranged from $2.5 \%$ (N3)-70\% (N2), with a maximum persistence of 98 days. Second, 265 N2-N5 nymphs were fed on blood containing $0.0015 \mathrm{M} \mathrm{CrCl}$. Cr marker positivity ranged up to $93 \%$ (N5), with a maximum persistence of 119 days. Finally, we blood fed $213 \mathrm{~T}$. brasiliensis to investigate whether $\mathrm{CrCl}_{3}$ altered the biology of this insect. The developmental time of $\mathrm{T}$. brasiliensis was unaltered, but the survival of the Cr-marked group was lower than that of the control group. Differences in the mean fecundity of the control (mean of 156.1) and experimental (mean of 135.6) groups were not statistically significant and 100\% of the egg batches of females Cr-marked as nymphs were positive. In conclusion, $\mathrm{CrCl}_{3}$ is a useful tool for marking T. brasiliensis nymphs due to its high positivity and persistence.

Key words: Triatoma brasiliensis - marking - survival - fecundity - development

Chagas disease, also called American trypanosomiasis, is often considered a disease of poverty that mainly occurs in rural areas in the Americas, from the southern part of the USA to Argentina and Chile. The etiological agent of Chagas disease is the flagellate protozoan Trypanosoma cruzi, which is commonly transmitted to humans and other mammals by the blood-sucking insects of the subfamily Triatominae. Currently, from the approximately 140 described triatomine species, 61 of them are located in Brazil, where the richness of the biome contributes to insect diversity throughout the country (Galvão et al. 2003). Similar to any other infectious disease transmitted by vectors, the study of the biology of this insect and its vectorial capacity is a powerful tool to enhance the knowledge about Chagas disease transmission dynamics.

Triatoma brasiliensis is considered the main vector of Chagas disease in the Northeast Region of Brazil, where it colonises both sylvatic and domestic environments, but is more frequently collected in peridomestic areas (Sarquis et al. 2004, Almeida et al. 2008, de la Fuente et al. 2008, Gonçalves et al. 2009). T. brasiliensis is usually widespread throughout sylvatic ecotopes, particularly in rock piles associated with a wide range of small mammals (Alencar 1987). In the peridomestic environment, it is fre-

+ Corresponding author: freitas@ioc.fiocruz.br

Received 24 September 2010

Accepted 16 December 2010 quently found in places such as goat and sheep corrals, pigpens and chicken coops. Inside dwellings, T. brasiliensis finds suitable hiding places in crevices in mud-brick walls, in dark places among boxes, behind pictures, in beds and in roofs (Rozendaal 1997, Sarquis et al. 2006).

Field studies regarding Chagas disease vector biology are scarce. For instance, studies on triatomine movement have been largely based on molecular and indirect approaches such as microsatellite markers and Random Amplification of Polymorphic DNA rather than on direct estimates from mark-release-recapture experiments (Borges et al. 2005, Noireau et al. 2005, Dumonteil et al. 2007, Richer et al. 2007, Harry et al. 2009, Cortez et al. 2010). Some studies have considered the active dispersal or flight activity of adult Triatoma infestans, which until few years ago used to be considered the main vector of Chagas disease throughout the southern part of Latin America (Lehane \& Schofield 1981, Schweigmann et al. 1988, Schofield et al. 1992, Noireau 2009). On the other hand, even less is known about nymph dispersal activity, a neglected subject that has relevant implications for vector use of sylvatic, peridomestic and domestic environments and consequently for disease dynamics. We believe that the main reason for this lack is the absence of a simple, reliable and direct method to mark triatomines (especially nymphs) in their natural habitat.

One of the most frequently used trace element markers for insects is the chloride $(\mathrm{Cl})$ form of rubidium $(\mathrm{Rb})$ $(\mathrm{RbCl}) . \mathrm{Rb}$ is an alkali metal that is non-toxic to plants, insects and other animals (Kimsey \& Kimsey 1984, Anderson et al. 1990). There are several techniques to mark insects with $\mathrm{Rb}$, each one with their own advantages and disadvantages. $\mathrm{Rb}$ can be sprayed on host plants to 
mark phytophagous insects, added to the water in which insect larvae are reared or to artificial diets or injected into vertebrate hosts and subsequently detected in the body or eggs of haematophagous insects that blood fed on them (Hagler \& Jackson 2001). Despite the potential role of chromium chloride $\left(\mathrm{CrCl}_{3}\right)$ in marking insects, this putative marker remains underexplored. Instead, $\mathrm{RbCl}$ has been largely used as a marker for the study of several biological parameters of blood-sucking vectors, from feeding and oviposition behaviours to dispersal estimates under field conditions (Kimsey \& Kimsey 1984, Anderson et al. 1990, Holbrook 1995, Reiter et al. 1995, Maciel-deFreitas et al. 2004, 2006). For instance, Reiter et al. (1995) monitored Aedes aegypti dispersal during oviposition in Puerto Rico after labelling female eggs with $\mathrm{RbCl}$.

In order to address nymph ecology under natural conditions, we evaluated the efficiency, reliability and persistence of marking T. brasiliensis nymphs with $\mathrm{RbCl}$ and $\mathrm{CrCl}_{3}$. We also investigated the possible effects that this marking may have on the longevity, survival and fecundity of marked insects and assessed if $\mathrm{Cr}$ marks also persists in the eggs laid by females that developed from marked nymphs.

\section{SUBJECTS, MATERIALS AND METHODS}

Triatomines - The T. brasiliensis used in this study were derived from a field collection that was previously carried out in an endemic area situated in the rural semiarid region of Jaguaruana, state of Ceará, Northeast Region of Brazil (4'50'14''S 37046'55'W). The nymphs and adults used in the experiments were the F1 generation of field-collected specimens and were raised and maintained in the laboratory at $28.6 \pm 2.7^{\circ} \mathrm{C}$ and $77.7 \pm$ $10 \%$ relative humidity.

Persistence of $\mathrm{RbCl}$ in triatomines - In order to address the persistence of $\mathrm{RbCl}$ in $T$. brasiliensis nymphs, we offered defibrinated sheep blood mixed with $0.025 \mathrm{M}$ $\mathrm{RbCl}$ at $37^{\circ} \mathrm{C}$ to 400 triatomines from the $\mathrm{N} 2-\mathrm{N} 5$ stages $(100$ individuals per stage: $\mathrm{N} 2=77, \mathrm{~N} 3=40, \mathrm{~N} 4=32$, $\mathrm{N} 5=50$ ) for 60 min by means of an artificial feeding apparatus (Rutledge et al. 1964). $\mathrm{RbCl}$ at a concentration of $0.025 \mathrm{M}$ has been previously used to mark mosquitoes, such as Ae. aegypti and Aedes albopictus, and we assumed that the same concentration would be effective for triatomines as it was to mosquitoes (Maciel-deFreitas et al. 2004, 2006). All triatomines that had been visually confirmed to have fed on the blood with 0.025 $\mathrm{M} \mathrm{RbCl}$ were recorded. These triatomines were kept together in plastic vials with folded filter paper $(10$ x 15 $\mathrm{cm}$ ) and nylon mesh covers. The persistence of $0.025 \mathrm{M}$ $\mathrm{RbCl}$ marking was assessed by randomly sampling five individuals from each vial per week, starting one week after blood feeding and ending when no triatomines were left for sampling. Subsequent Rb-free blood feedings were offered every 15 days using the same method described above.

Ideal concentration and persistence of $\mathrm{CrCl}_{3}$ - Because no published studies used $\mathrm{CrCl}_{3}$ to mark bloodsucking vectors, we first had to assess the ideal concentration to mark triatomines. With that aim, we offered defibrinated sheep blood mixed with the following $\mathrm{CrCl}_{3}$ concentrations to $30 \mathrm{~N} 3$ nymphs: 10 were fed with 0.0001 M, 10 with $0.0007 \mathrm{M}$ and 10 with $0.0015 \mathrm{M}$. Seven days later, individuals were evaluated to be either positive or negative for $\mathrm{Cr}$.

After optimising the concentration of $\mathrm{CrCl}_{3}$ to mark the triatomines, we evaluated its persistence in the vector body by offering defibrinated sheep blood mixed with $0.0015 \mathrm{M} \mathrm{CrCl}_{3}$ to triatomines from the $\mathrm{N} 2-\mathrm{N} 5$ stages $(\mathrm{N} 2=65, \mathrm{~N} 3=85, \mathrm{~N} 4=65, \mathrm{~N} 5=50)$. We used the same sampling procedure as described for $\mathrm{Rb}$.

Impact of $\mathrm{CrCl}_{3}$ on triatomine biology - For the subsequent experiments, recently hatched $T$. brasiliensis first instar nymphs were fed with a mix of blood and 0.0015 $\mathrm{M} \mathrm{CrCl}_{3}$, and the engorged nymphs were monitored daily until the nymphs died or became adults. Through this procedure, we were able to determine the development time of marked and control insects from the first instar nymph (N1) stage to the adult stage. We also recorded adult longevity and determined survival curves. Female insects that survived to the adult stage were monitored to determine their fecundity. In this experiment, $125 \mathrm{~N} 1 \mathrm{in}-$ sects were in the control group and $128 \mathrm{~N} 1$ insects were in the experimental group.

Longevity and survival - Triatomines were monitored daily to assess insect mortality. The lethal time 50 $\left(\mathrm{LT}_{50}\right)$ value, when $50 \%$ of the triatomines had died, was compared between the experimental and control groups using a t-test. Survival curves of $\mathrm{Cr}$ experimental and control groups were compared using a log-rank test, a nonparametric test for the comparison of the survival curve of two or more groups (Kleinbaum 1996). After initially checking with a Shapiro-Walk test, we used a nonparametric test to show that the mortality data was not distributed normally ( $\mathrm{W}=0.847, \mathrm{p}<0.001$ ). Survival data was analyzed with XLSTAT 2010.4 software.

Development time - The time spent between each moulting stage during the triatomine life cycle was recorded and compared using an unpaired t-test with Welch correction due to the unequal variances between groups.

Fecundity - The number of eggs laid by adult females that were marked with $\mathrm{CrCl}_{3}$ as nymphs were recorded and comparisons between groups were performed using an unpaired t-test.

$\mathrm{RbCl}$ and $\mathrm{CrCl}_{3}$ detection - For the detection of $\mathrm{RbCl}$ and $\mathrm{CrCl}_{3}$, each triatomine was individually heated to $100^{\circ} \mathrm{C}$ in $2 \mathrm{~mL}$ of $65 \%$ nitric acid. Each sample was examined in an atomic emission spectrophotometer at a wavelength of either $780 \mathrm{~nm}(\mathrm{Rb})$ or $267.72 \mathrm{~nm}$ (Cr) (ICP Optima 3300 DV Perkin Elmer) after complete evaporation of the acid and addition of $1 \mathrm{~mL}$ of distilled water. In order to calibrate the spectrophotometer, three triatomines from the colony, i.e., free of $\mathrm{Rb}$ and $\mathrm{Cr}$, were used as controls after every 10 samples. Mean absorbance values and standard errors for the controls were used to estimate a confidence interval $(\alpha=0.01)$. Triatomines from the experimental group whose absorbance values were higher than the limit calculated above were considered positive for $\mathrm{RbCl}$ or $\mathrm{CrCl}_{3}$ labelling. 
$\mathrm{CrCl}_{3}$ detection in $\mathrm{T}$. brasiliensis eggs - The egg batches laid by marked adult females were tested for the presence of $\mathrm{Cr}$ against egg batches from the control group. The egg batches varied in size, from 2-32 eggs. Due to this difference, before performing an unpaired t-test to compare the mean absorbance values in the experimental and control batches, we corrected the absorbance values observed by dividing batch absorbance by the number of eggs in each batch.

\section{RESULTS}

Aspects of $0.025 \mathrm{M} \mathrm{RbCl}$ marking - The frequency of the Rb-positive insects varied significantly between stages, ranging from $2.5 \%$ in N3-70\% in N2 (Table I). The highest $\mathrm{RbCl}$ persistence was observed in $\mathrm{N} 2$; five N2 insects were still positive 98 days post blood meal (pbm). However, these results were highly variable between triatomine stages, suggesting an inconsistency in $0.025 \mathrm{M} \mathrm{RbCl}$ efficiency and persistence.

Ideal concentration of $\mathrm{CrCl}_{3}$ - Significant differences were observed between the three $\mathrm{CrCl}_{3}$ concentrations tested. In the $0.0001 \mathrm{M}$ and $0.0007 \mathrm{M}$ treatments, we observed that only two $(20 \%)$ and three $(30 \%) \mathrm{N} 3$ triatomines were positive, respectively. However, all N3 individuals $(\mathrm{N}=10)$ that received $0.0015 \mathrm{M} \mathrm{CrCl}_{3}$ were positive one week pbm. Therefore, to evaluate the persistence and impact of $\mathrm{CrCl}_{3}$ in the subsequent experiments, only $0.0015 \mathrm{M} \mathrm{CrCl}_{3}$ was used.

Positivity and persistence of $0.0015 \mathrm{M} \mathrm{CrCl}_{3}-\mathrm{We}$ offered $0.0015 \mathrm{M} \mathrm{CrCl}_{3}$ to 265 nymphs from N2 to N5 to investigate the persistence of this marker in T. brasiliensis, but only 173 individuals were engorged with blood plus $\mathrm{Cr}$ (Table II). We observed an increase in nymph positivity to $\mathrm{CrCl}_{3}$ in relation to insect life cycle, from $61.5 \%$ in $\mathrm{N} 2$ to $93 \%$ in $\mathrm{N} 5 . \mathrm{CrCl}_{3}$ marking was highly persistent in triatomines; N3 individuals were positive up to 119 days pbm (Table II).

Longevity and survival - The survival curve of Crmarked insects was significantly different from control insects (log-rank $=12.1, \mathrm{df}=1, \mathrm{p}<0.01)$ (Figure). This result suggests that $\mathrm{Cr}$ marking may decrease triatomine survivorship. This hypothesis is reinforced by our observation that the $\mathrm{LT}_{50}$ was higher in control insects than in

\section{TABLE I}

Efficiency and persistence of rubidium chloride $(\mathrm{RbCl})$ $0.025 \mathrm{M}$ in marking Triatoma brasiliensis nymphs

\begin{tabular}{lccc}
\hline $\begin{array}{l}\text { Nymph } \\
\text { stage }\end{array}$ & $\begin{array}{c}\text { Engorged with } \\
\text { blood + RbCl }\end{array}$ & Positivity (\%) & $\begin{array}{c}\text { RbCl 0.025M } \\
\text { persistence } \\
\text { (days) }\end{array}$ \\
\hline N2 & 70 & 70 & 98 \\
N3 & 40 & 2.5 & 70 \\
N4 & 32 & 12.5 & 49 \\
N5 & 50 & 42 & 28 \\
\hline
\end{tabular}

blood with $\mathrm{RbCl}$ was offered for 100 individuals per stage.
TABLE II

Efficiency and persistence of chromium chloride $\left(\mathrm{CrCl}_{3}\right)$ $0.0015 \mathrm{M}$ in marking Triatoma brasiliensis nymphs

\begin{tabular}{lccc}
\hline $\begin{array}{l}\text { Nymph } \\
\text { stage }\end{array}$ & $\begin{array}{c}\text { Engorged with } \\
\text { blood }+\mathrm{CrCl}_{3} / \text { total }\end{array}$ & $\begin{array}{c}\text { Positivity } \\
(\%)\end{array}$ & $\begin{array}{c}\mathrm{CrCl}_{3} 0.0015 \mathrm{M} \\
\text { persistence } \\
\text { (days) }\end{array}$ \\
\hline N2 & $39 / 65$ & 61.5 & 91 \\
N3 & $65 / 85$ & 73 & 119 \\
N4 & $55 / 65$ & 83 & 91 \\
N5 & $14 / 50$ & 93 & 63 \\
\hline
\end{tabular}

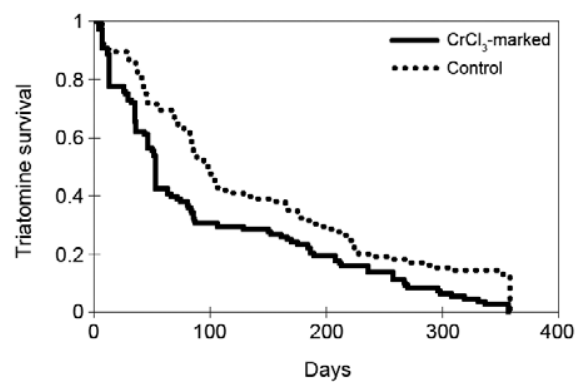

Survival curves of Triatoma brasiliensis marked as N1 with chromium chloride $\left(\mathrm{CrCl}_{3}\right)$ 0.0015M and controls. Some individuals survived up to the adult stage.

marked insects ( $\mathrm{LT}_{50}$ Cr-marked: 53 days; $\mathrm{LT}_{50}$ control: 98 days). The maximum longevity of the experimental and control groups was 357 and 358 days, respectively.

Development time - Overall, the time spent between moulting stages was higher in the individuals marked with $\mathrm{CrCl}_{3}$ than in the controls (Table III). However, this difference was only significant in N2; marked individuals remained in N2 for $34.4 \pm 4.5$ days and controls remained in $\mathrm{N} 2$ for $43.2 \pm 12.9$ days $(\mathrm{p}=0.011)$.

Fecundity - A total of 26 female triatomines reached the adult stage and had their fecundity monitored. Females from the control group laid 156.1 eggs, while those from experimental group 135.6 eggs; this difference was not statistically significant $(\mathrm{t}=0.648, \mathrm{df}=9, \mathrm{p}=0.533)$.

$\mathrm{CrCl}_{3}$ detection in $\mathrm{T}$. brasiliensis eggs - We detected $\mathrm{Cr}$ in $100 \%$ of the egg batches of marked females, reinforcing the potential role of $\mathrm{CrCl}_{3}$ as a persistent marker of $T$. brasiliensis.

\section{DISCUSSION}

A wide variety of marking techniques has been used to estimate the biological parameters of medically and agriculturally important insects (Hagler \& Jackson 2001, Silver 2008). In order to evaluate their usefulness, they must have an acceptable duration in the organism, their application must not affect the behaviour of the organism, (e.g., altering their chances of being killed by predators) and the released insects must become thoroughly 
TABLE III

Range and mean \pm standard deviation (SD) of development time of Triatoma brasiliensis nymphs marked with chromium chloride $\left(\mathrm{CrCl}_{3}\right) 0.0015 \mathrm{M}$ and controls ${ }^{a}$

\begin{tabular}{|c|c|c|c|c|c|}
\hline \multirow[b]{2}{*}{$\begin{array}{l}\text { Nymph } \\
\text { Stage }\end{array}$} & \multicolumn{2}{|c|}{ Control group } & \multicolumn{2}{|c|}{$\mathrm{CrCl}_{3}$ marked group } & \multirow[b]{2}{*}{$\begin{array}{l}\mathrm{p} \text { value } \\
(\mathrm{t} \text { test })\end{array}$} \\
\hline & Mean $\pm \mathrm{SD}$ & $\begin{array}{c}\text { Molting range (min-max) } \\
\text { (days) }\end{array}$ & Mean \pm SD & $\begin{array}{c}\text { Molting range (min-max) } \\
\text { (days) }\end{array}$ & \\
\hline N1-N2 & $38.4 \pm 6.8$ & $27-51$ & $40.4 \pm 8.8$ & $27-53$ & 0.277 \\
\hline N2-N3 & $34.4 \pm 4.5$ & $29-43$ & $43.2 \pm 12.9$ & $24-58$ & 0.011 \\
\hline N3-N4 & $43.4 \pm 8.9$ & $33-63$ & $46.5 \pm 12.3$ & $30-74$ & 0.417 \\
\hline N4-N5 & $45.9 \pm 6.3$ & $36-57$ & $48.9 \pm 11.9$ & $30-68$ & 0.229 \\
\hline N5-adults & $81.5 \pm 21.8$ & $50-140$ & $94.5 \pm 28.2$ & $55-127$ & 0.29 \\
\hline
\end{tabular}

$a$ : free of trace element.

mixed with the local non-marked population (Southwood 1978). In this report, we evaluated the persistence and efficiency of $0.025 \mathrm{M} \mathrm{RbCl}$ and $0.0015 \mathrm{M} \mathrm{CrCl}_{3}$ to mark T. brasiliensis nymphs.

Trace elements have been successfully used to mark at least eight orders and 30 families of insects, with $\mathrm{RbCl}$ being the most frequently used marker (Hagler \& Jackson 2001, Maciel-de-Freitas et al. 2004, 2006). However, our results showed that $\mathrm{RbCl}$ had a very variable positivity and a decreasing persistence with the stage of $T$. brasiliensis. Only individuals marked as N2 presented a satisfactory positivity, while less than $15 \%$ of individuals marked as N3 and N4 maintained their positivity. The failure of $\mathrm{RbCl}$ to be used as a marker of T. brasiliensis was unexpected due to the large reported history of this trace element in marking both phytophagous and haematophagous insects (Hagler \& Jackson 2001).

A relatively high frequency of positive N2-N5 triatomines was obtained with $0.0015 \mathrm{M} \mathrm{CrCl}_{3}$. The increase in positivity in N2-N5 insects may be easily explained; large (N4-N5) individuals probably consumed larger blood meals and, thus, ingested more $\mathrm{Cr}$ than small (N2-N3) individuals (Hagler \& Jackson 2001). In addition, the $\mathrm{Cr}$ marker also presented high persistence in T. brasiliensis. Due to the high frequency of positivity combined with the high persistence observed for the Cr marker, we conclude that $\mathrm{CrCl}_{3}$ is a potentially useful tool to mark triatomines. In fact, its high persistence (around 3-4 months pbm) allows for the design of mark-release-recapture experiments to study the population dynamics of $T$. brasiliensis in the field. Mark-release-recapture experiments are powerful tools to explore aspects of triatomine vector biology, such as insect survival, dispersal and movement to or from endemic areas (Lehane \& Schofield 1981, Schweigmann et al. 1988, Schofield et al. 1992).

One possible drawback of using $\mathrm{Cr}$ as a marker in field conditions is that marking with this trace element was found to negatively affect the survival of $T$. brasiliensis. However, triatomines have a long lifespan in comparison to other disease vectors; sometimes adults live for two years (Oliveira et al. 2009). Therefore, this shortcoming is probably not sufficient to jeopardise the applicability of a mark-release-recapture experiment to determine aspects of vector biology under field conditions in endemic areas. The ingestion of a significant amount of $\mathrm{Cr}$ possibly alters triatomine metabolism. The injection of $\mathrm{Cr}$ has been shown to change the activity of antioxidant enzymes, such as superoxide dismutase, catalase and guaiacol peroxidase, in the insect Oxya chinensis (Orthoptera: Acrididae), increasing oxidative stress and, consequently, insect mortality ( $\mathrm{Li}$ et al. 2005). The biochemical or molecular reasons for the decrease in the survival of $\mathrm{Cr}$ marked T. brasiliensis compared to the control insects remains unclear, but an extrapolation from data gathered on O. chinensis seems reasonable (Li et al. 2005).

With the exception of $\mathrm{N} 2$, the time spent by $\mathrm{Cr}$ marked triatomines in each moulting stage was statistically similar to controls and in laboratory controlled experiments that measured this variable (Oliveira et al. 2010). The difference observed only in N2 individuals is difficult to explain. Although $\mathrm{Cr}$-marked insects often had a slower development time than controls, this difference was not statistically significant. Overall, we can assume that $\mathrm{Cr}$ increased $\mathrm{T}$. brasiliensis mortality, but those vectors that survived presented a slight modification in their development time.

The two trace elements used in these experiments to mark $T$. brasiliensis ( $\mathrm{Rb}$ and $\mathrm{Cr}$ ) produced different results when mixed with blood and ingested by triatomines. $\mathrm{RbCl}$ showed low persistence and no reliability. On the other hand, the results from the $\mathrm{CrCl}_{3}$ experiments were more consistent; the frequency of positivity was high, the marking persisted up to 119 days pbm, the development time was not seriously affected and the adult fecundity remained unaltered. The 100\% persistence of the marker in the egg batches laid by females marked as nymphs may contribute to the long-term presence of $\mathrm{Cr}$ in the studied area. However, $\mathrm{Cr}$-marked individuals had a significant decrease in their lifespan. Because mark-release-recapture experiments are extremely useful for the evaluation of biological parameters of vector ecology, the limitations of the Cr-marking method due to decreased survival rate can be disregarded. 


\section{REFERENCES}

Alencar JE 1987. História natural da doença de Chagas no estado do Ceará, Imprensa Universidade da UFC, Fortaleza, 341 pp.

Almeida CE, Pacheco RS, Haag K, Dupas S, Dotson EM, Costa J 2008. Inferring from the Cyt B gene the Triatoma brasiliensis Neiva, 1911 (Hemiptera: Reduviidae: Triatominae) genetic structure and domiciliary infestation in the state of Paraíba, Brazil. Am J Trop Med Hyg 78: 791-802.

Anderson RA, Edman JD, Scott TW 1990. Rubidium and cesium as host blood-markers to study multiple blood-feeding by mosquitoes (Diptera: Culicidae). J Med Entomol 27: 999-1001.

Borges EC, Dujardin JP, Schofield CJ, Romanha AJ, Diotaiuti L 2005. Dynamics between sylvatic, peridomestic and domestic populations of Triatoma brasiliensis (Hemiptera: Reduviidae) in Ceará state, Northeastern Brazil. Acta Trop 93: 119-126.

Cortez MR, Monteiro FA, Noireau F 2010. New insights on the spread of Triatoma infestans from Bolivia - Implications for Chagas disease emergence in the Southern Cone. Infect Genet Evol 10: 350-353.

de la Fuente AL, Dias-Lima A, Lopes CM, Emperaire L, Walter A, Ferreira A, Sherlock I, Noireau F 2008. Behavioral plasticity of Triatominae related to habitat selection in Northeast Brazil. J Med Entomol 45: 14-19.

Dumonteil E, Tripet F, Ramirez-Sierra MJ, Payet V, Lanzaro G, Menu F 2007. Assessment of Triatoma dimidiata dispersal in the Yucatan peninsula of Mexico by morphometry and microsatellite markers. Am J Trop Med Hyg 76: 930-937.

Galvão C, Carcavallo R, Rocha DS, Juberg J 2003. A checklist of the current valid species of the subfamily Triatominae Jeannel, 1919 (Hemiptera: Reduviidae) and their geographical distribution, with nomenclatural and taxonomic notes. Zootaxa 202: 1-36.

Gonçalves TCM, Freitas ALC, Freitas SPC 2009. Surveillance of Chagas disease vectors in municipalities of the state of Ceará, Brazil. Mem Inst Oswaldo Cruz 104: 1159-1164.

Hagler JR, Jackson CG 2001. Methods for marking insects: current techniques and future prospects. Annu Rev Entomol 46: 511-543.

Harry M, Dupont L, Quartier M, Diotaiuti L, Walter A, Romana C 2009. New perspectives for population genetics of Chagas' disease vectors in the Northeastern Brazil: isolation of polymorphic microsatellite markers in Triatoma brasiliensis. Infect Genet Evol 9: 633-637.

Holbrook FR 1995. Rubidium in female Culicoides variipennis sonorensis (Diptera: Ceratopogonidae) after engorgement on a rubidium-treated host. J Med Entomol 32: 387-389.

Kimsey RB, Kimsey PB 1984. Identification of arthropod blood meals using rubidium as a marker: a preliminary study. $J$ Med Entomol 21: 714-719.

Kleinbaum DG 1996. Survival analysis: a self-learning text, Springer Verlag, New York, p. 45-82.

Lehane MJ, Schofield CJ 1981. Field experiments of dispersive flight by Triatoma infestans. Trans R Soc Trop Med Hyg 75: 399-400.

Li LJ, Zhang F, Liu XM, Guo YP, Ma EB 2005. Oxidative stress related enzymes in response to chromium (VI) toxicity in Oxya chinensis (Orthoptera: Acridoidae). J Environ Sci (China) 17: 823-826.
Maciel-de-Freitas R, Gonçalves JM, Lourenço-de-Oliveira R 2004. Efficiency of rubidium marking in Aedes albopictus (Diptera: Culicidae): preliminary evaluation on persistence of egg labeling, survival and fecundity of marked female. Mem Inst Oswaldo Cruz 99: 823-827.

Maciel-de-Freitas R, Neto RB, Gonçalves JM, Codeço CT, Lourençode-Oliveira R 2006. Movement of dengue vectors between the human modified environment and an urban forest in Rio de Janeiro. J Med Entomol 43: 1112-1120.

Noireau F 2009. Wild Triatoma infestans, a potential threat that needs to be monitored. Mem Inst Oswaldo Cruz 104 (Suppl. I): 60-64.

Noireau F, Cortez MG, Monteiro FA, Jansen AM, Torrico F 2005. Can wild Triatoma infestans foci in Bolivia jeopardize Chagas disease control efforts? Trends Parasitol 21: 7-10.

Oliveira LS, Duarte R, Lima MM, Sarquis O 2009. Aspectos da biologia de populações silvestres e peridomiciliares de Triatoma brasiliensis (Hemiptera; Reduviidae). Rev Patol Trop 38: 722.

Oliveira TG, Carvalho-Costa FA, Gomes TF, Sarquis O, Sposina R, Lima MM 2010. Developmental and reproductive patterns of Triatoma brasiliensis infected with Trypanosoma cruzi under laboratory conditions. Mem Inst Oswaldo Cruz 105: 1057-1060.

Reiter P, Amador MA, Anderson RA, Clark GG 1995. Short report: dispersal of Aedes aegypti in an urban area after blood feeding as demonstrated by rubidium-marked eggs. Am J Trop Med Hyg 52: $177-179$.

Richer W, Kengne P, Cortez MR, Perrineau MM, Cohuet A, Fontenille D, Noireau F 2007. Active dispersal by wild Triatoma infestans in the Bolivian Andes. Trop Med Int Health 12: 759-764.

Rozendaal JA 1997. Triatomine bugs. In JA Rozendaal, Vector control - methods for use by individual and communities, WHO, Geneva, p. 210-236.

Rutledge LC, Ward RA, Gould DJ 1964. Studies on the feeding response of mosquitoes to nutrition solutions in a new membrane feeder. Mosq News 24: 407-419.

Sarquis O, Borges-Pereira J, Mac Cord JR, Gomes TF, Cabello PH, Lima MM 2004. Epidemiology of Chagas disease in Jaguaruana, Ceará, Brazil. I. Presence of triatomines and index of Trypanosoma cruzi infection in four localities of a rural area. Mem Inst Oswaldo Cruz 99: 263-270.

Sarquis O, Sposina R, Oliveira TG, Mac Cord JR, Cabello PH, BorgesPereira J, Lima MM 2006. Aspects of peridomiciliary ecotopes in rural areas of Northeastern Brazil associated to triatomine (Hemiptera, Reduviidae) infestation, vectors of Chagas disease. Mem Inst Oswaldo Cruz 101: 143-147.

Schofield CJ, Lehane MJ, McEwen P, Catala SS, Gorla DE 1992. Dispersive flight by Triatoma infestans under natural climatic conditions in Argentina. Med Vet Entomol 6: 51-56.

Schweigmann N, Vallvé S, Muscio O, Ghillini M, Alberti A, Wisnivesky-Colli C 1988. Dispersal flight by Triatoma infestans in an arid area of Argentina. Med Vet Entomol 2: 401-404.

Silver JB 2008. Mosquito ecology: field sampling methods, Springer, Dordrecht, $1498 \mathrm{pp}$.

Southwood TRE 1978. Ecological methods with particular reference to the study of insect populations, Chapman \& Hall, London, 548 pp. 